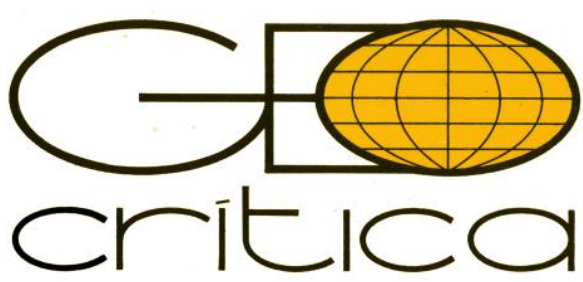

\title{
A REPRESENTAÇAO DO GENOCÍDIO ARMÊNIO NO NEW YORK TIMES (1915)
}

\author{
Daniela Emilena Santiago Dias de Oliveira \\ Docente na Universidade Paulista (UNIP) campus Assis, São Paulo \\ Doutoranda em História na FCL/UNESP, São Paulo \\ santiago.dani@yahoo.com.br \\ Gabriel Santiago de Cristo \\ Graduando em História na Universidade Estadual de Santa Cruz, campus Ilhéus, Bahia \\ gabrielsantiagodiasoliveira@gmail.com
}

\section{A representação do Genocídio Armênio no New York Times, 1915 (Resumo)}

O jornal New York Times é na atualidade um dos principais dispositivos de difusão de informação no mundo. Apesar de originalmente americano, é referência na circulação de ideias em vários países. Com tal, mostra-se um jornal extremamente combativo e polêmico, sendo essa sua principal característica desde a sua fundação. Nosso estudo sobre a produção deste jornal no ano de 1915 analisa todos os textos que abordaram o genocídio armênio, em curso naquele período. Constatamos que o New York Times assumiu, no ano de 1915, uma postura de denunciar ao mundo as crueldades pelas quais passaram o povo armênio além de destacar a necessidade de intervenção de outros Estados frente a situação que se deflagrava na Turquia. A análise deste jornal nos permitiu conhecer ainda os meios usados pelos turcos para submeter os armênios, ressaltando assim a crueldade dessas práticas.

Palavras-chave: Genocídio; Armênio; New York Times.

\section{The Armenian Genocide Representation in the New York Times, 19 I 5 (Abstract)}

The New York Times is currently one of the world's leading information dissemination devices. Although originally American, it is a reference of the circulation of ideas in several countries. With this, it proves to be an extremely combative and controversial newspaper being its main feature since its foundation. Our study of the production of the newspaper in 1915 analyzed all the texts that addressed the Armenian genocide, underway at that time. We note that in the year 1915, the New York Times took a stance of denouncing to the world the cruelties that the Armenian people went through, and always emphasized the need for intervention by other states in the face of the situation in Turkey. The analysis of the newspaper also allowed us to know the means used by the Turks to submit Armenians, thus highlighting the cruelty of these practices.

Keywords: Genocide; Armenian; New York Times. 
Ao ingressarmos no curso "Tópicos Especiais: História, Imprensa e Regimes Autoritários", no primeiro semestre de 2019, atividade vinculada ao Programa de Pós-Graduação em História da Universidade Estadual Paulista "Júlio de Mesquita Filho", tivemos contato com vários eventos relacionados aos regimes autoritários que se manifestaram pelo mundo a partir da primeira pósguerra. Dentre esses fenômenos podemos citar o genocídio armênio. Para analisá-lo realizamos pesquisas em textos e artigos disponíveis em internet e em outras fontes que nos permitiram ampliar a perspectiva sobre o mesmo. Assim, o tema foi se mostrando cada vez mais interessante e motivou a elaboração deste texto.

O amplo rol de atrocidades que levou ao genocídio do povo armênio na Turquia ocorreu durante a Primeira Guerra Mundial, quando os olhos do mundo estavam voltados para a mesma. Os turcos aproveitaram desse contexto bélico para impor sua perseguição ${ }^{1}$.

Segundo Carlos Antaramián (2016), este genocídio ocorreu durante o Império Otomano, que naquele contexto era comandado pelo partido denominado Jovens Turcos, e que dizimou entre 1915 e 1923 cerca de 800.000 armênios.

O objetivo do partido Jovens Turcos, que paradoxalmente, chegou ao poder com o apoio dos armênios no ano de 1908, enfatizando sentimentos de nacionalismo exacerbado e defendendo uma suposta nação turca, era consolidar um Estado Turco, e, para isso buscou exterminar não só os armênios, mas também assírios e gregos. Os valores religiosos também serviram de aporte para que este partido pudesse "justificar" suas escolhas por um certo perfil de povo idealizado para a Turquia.

Apesar de que a Turquia continue negando, até os dias atuais, que o genocídio do povo armênio tivesse acontecido, a imprensa de alguns países retratou o que acontecia naquele território. Antaramian (2016) indica que o New York Times publicou no ano de 1915 um total de 194 artigos que denunciavam a situação do povo armênio neste país. Isso despertou o nosso interesse em identificar quais seriam as tratativas do jornal em relação a este genocídio. Além do que cabe à pesquisa histórica deixar essas realidades ainda mais claras, sobretudo considerando-se o negaciosnimo referente a tais eventos.

Decidimos analisar artigos publicados no New York Times no ano de 1915, algo que foi possível por meio da consulta dos jornais online, os quais estão disponíveis para acesso via site de arquivo do jornal. ${ }^{2}$ No entanto, no sistema de acervo desse jornal, identificamos apenas 64 textos dos 194 artigos citados por Antaramian (2016). É possível que os arquivos digitalizados não representem a totalidade daqueles que circularam em 1915. De tal forma, delimitamos como amostra os 64 artigos, os quais foram copiados da base de dados do jornal, traduzidos e separados segundo sua frequência e temática. Como o site dos artigos não possuía dispositivo de busca foi necessário checar todos os meses, artigo a artigo para separar nossa amostra.

Atendendo as finalidades acadêmicas para a composição do artigo, teceremos, inicialmente, considerações acerca do jornal New York Times; a seguir, elaboraremos uma análise sobre o contexto no qual ocorreu o genocídio armênio; e, finalmente, apresentaremos a discussão dos dados obtidos por meio de nosso estudo em relação à representação do genocídio armênio no jornal estudado. Não pretendemos realizar uma análise crítica e aprofundada dos periódicos,

\footnotetext{
${ }^{1}$ Antaramián, 2016, Oliveira e Rodrigues, 2018.

2 Todos os artigos do jornal New York Times usados nesse texto estão disponíveis para acesso on line. Disponível em <https://spiderbites.nytimes.com/1915/articles_1915_05_00000.html>. Acesso em 20 de jul. de 2019.
} 
mas buscamos reforçar a importância que o impresso teve em mostrar à sociedade uma realidade que na época buscou-se esconder.

\section{O New York Times: delimitando a área social da pesquisa}

Sempre que estudamos um impresso, conforme Roger Chartier (1988), é necessário identificar a chamada área social do mesmo. Por área social o autor busca designar condições de produção, os processos de produção e de circulação de um determinado impresso. Assim, para compreender a fonte pesquisada, deve-se evocar a necessidade de identificar aspectos das condições e processos de produção e também de circulação do New York Times em 1915. Um destes aspectos é a escassez de fontes sobre o jornal o que dificulta, em grande medida, a composição desse tema. De tal maneira que as fontes que identificamos trazem informações sobre um período do jornal e não são específicas do ano de 1915. Apesar disto, os dados sobre o desenvolvimento histórico do jornal nos permitem realizar a identificação e a análise de sua área social e nos indicam as características culturais de quem a produziu.

O New York Times foi fundado na cidade de Nova York em 18 de setembro de 1851 por Henry Jarvis Raymond e por George Jones e inicialmente era publicado diariamente, exceto aos domingos. No ano de 1896 foi comprado por Adolph Ochs, filho de imigrantes alemães e de antepassados judeus. Quando Ochs assumiu o jornal, ele promoveu uma mudança em seu editorial, que passava a ser organizado com notícias que buscavam inspirar e causar confiança nos leitores. A proposta do novo dono do periódico era publicar matérias que abordassem questões relacionadas às questões financeiras e de negócios, bem como ao ramo imobiliário e aos assuntos políticos ${ }^{3}$.

Com o falecimento de Adolph Ochs, sua filha Iphigene e seu esposo Arthur assumiram a gestão do jornal que, tempos depois, foi organizado pelo filho do casal, também Arthur. Conforme José Rosamilton de Lima e Ivanaldo Oliveira dos Santos Filho (2012), esta condição conferiu ao New York Times a sua característica atual de constituir-se como um meio de comunicação que buscava apresentar ao público leitor uma característica de jornal sério e imparcial.

Nos anos 1940, o New York Times inseriu alguns elementos diferenciados em sua estrutura, como as palavras cruzadas e os espaços de moda, porém, a sua grande especificidade se constituiu em publicar textos de grande impacto junto aos leitores. Isso fez com que o periódico se tornasse uma grande referência para a economia, à vida social e, sobretudo, para a organização política nos Estados Unidos. Apesar de ter vivenciado uma grande crise financeira em 2008, como consequência da ampliação da internet e dos meios digitais de comunicação, hoje o New York Times faz parte do grupo New York Times Company, um verdadeiro conglomerado midiático responsável por um grande número de publicações impressas, por jornais veiculados digitalmente, por rádios e também por uma gama ampla de elementos midiáticos ${ }^{4}$.

Retornando ao nosso objetivo principal, as matérias concernentes ao genocídio do povo armênio, podemos inferir que neste período o New York Times estava sob a gestão de Adolph

\footnotetext{
${ }^{3}$ Lima, Santos Filho, 2012.

${ }^{4}$ Lima; Santos Filho, 2012.
} 
Ochs e que, portanto, sua característica era a de apresentar textos que atraíssem o leitor com informações tidas como verdadeiras, o que lhe dotava de um perfil informativo e de opinião.

Considerando que os jornais podem ter essas duas características, ser informativos ao transmitir uma notícia más também opinativos de modo a causar uma repercussão social em determinados momentos, e que as matérias representam em grande medida a perspectiva daqueles que dirigem os impressos e seus objetivos, a nosso ver, as publicações do New York Times sobre o genocídio armênio, além de ilustrar a perspectiva do mesmo, buscaram formar o pensamento crítico do leitor.

Outro aspecto interessante quando pensamos sobre os meios de comunicação, nesse caso do New York Times é que quanto mais leitores e maior a circulação, mais influente será o jornal no sentido de formar uma opinião social, coletiva. Infelizmente não temos dados sobre a tiragem do jornal que, em 1915 era diário, com exceção dos domingos, mas sabemos que naquela época já se constituía como uma das principais fontes impressas de informação nos Estados Unidos da América. Se levamos em consideração que para muitas pessoas, o jornal era, daquele período, a única forma de informação, há que reconhecer como extremamente relevante a atenção conferida ao genocídio armênio em suas matérias.

Tendo assim tais colocações arroladas, passamos à caracterização do que se convencionou nomear como genocídio armênio.

\section{O genocídio armênio}

De acordo com Antaramián (2016) o contexto que resultou no genocídio foi gerado a partir do momento em que o sultão Abdul- Hamed II passou a fortalecer o discurso de que haveria dois grupos na sociedade turca, os turcos mulçumanos e os cristãos armênios, e que estes últimos desejavam corromper e acabar com a nação turca ${ }^{5}$. Posição que também era defendida pelo partido Jovens Turcos.

Este contexto de instabilidade social, associado ao cenário bélico em que se encontrava Europa colaborou para o enfraquecimento do poder de Abdul- Hamed II e a consequente ampliação do prestígio do partido Jovens Turcos, que nesse embalo deram um golpe de Estado e assumiram o poder na Turquia ${ }^{6}$.

Outro acontecimento que contribuiu para a formação de uma convicção na qual os armênios deveriam ser repudiados foi a divulgação que dois turcos teriam sido assassinados por um armênio, um crime que teria alcançado grande visibilidade nacional. A repercussão deste episódio favoreceu a crença de que os armênios eram perigosos e levou o Partido Jovens Turcos a retomar o discurso de Abdul- Hamed II $^{7}$. Além disso começou a dissipar-se a ideia de que os armênios estariam organizando uma revolta separatista. Essa perspectiva ofereceu sustentação para a perseguição dos armênios cristãos por parte do Estado turco.

A difusão do nacionalismo como algo além do amor à pátria e a perspectiva de limpeza étnica e religiosa também passaram a ser apresentados como fundamentos para a ação de extermínio

\footnotetext{
${ }^{5}$ Amanda Muniz Oliveira e Horácio Wanderley Rodrigues, 2018.

${ }^{6}$ Conforme afirma Antaramián, 2016.

${ }^{7}$ Oliveira e Rodrigues, 2018.
} 
destes grupos. Antaramián (2016) assevera que povos como os assírios e os gregos também sofreram com esse extermínio, uma vez que por motivos étnicos e religiosos passaram a ser considerados como povos que não mereciam a confiança dos turcos. Segundo o autor "existe um grupo minoritário central o qual se despeja a fúria de sua neurose, mas, há também outros grupos minoritários que de igual forma sofrem o extermínio junto à não vitimizada" [tradução nossa $]^{89}$. O autor reforça que mesmo os armênios que se convertiam à religião muçulmana e aceitavam o novo regime, não eram considerados dignos de confiança.

Desta forma, a agressão aos povos armênios foi sustentada por um discurso que foi veiculado pelo Estado, aceito socialmente e que justificou as intervenções que passaram a ser consideradas legítimas. A ação de extermínio, precedida pelo discurso, foi um ato planejado e organizado no qual o sistema punitivo turco ocupava papel de destaque, conferindo concretude ao que fora idealizado. A matança passava a ser algo legalizado. O fato de ser planejado antecipadamente, deliberado e premeditado é um dos aspectos que confere a este fenômeno o caráter de genocídio. A justificativa também está assentada em motivo étnico, religioso ou racial e resulta na aniquilação de um povo.

Apesar de o genocídio armênio ainda não ter sido punido em nenhum tribunal internacional, ele é considerado um crime contra a Humanidade, posto que representa aberrações que foram cometidas contra seres humanos. Configura, a nosso ver, como uma ação que fere toda a humanidade. Ademais, além da perda de vidas, temos a perda de cultura de um povo que quase foi extinto.

No entanto, no contexto da sua ocorrência, como salienta Antaramián (2016), enquanto o genocídio caminhava a passos largos, se observava a inércia da maior parte dos Estados.

Partindo assim da questão percebida no cenário internacional, é interessante analisar a perspectiva de um jornal estadunidense e de como o mesmo descreveu esse massacre. Assim, no item subsequente apresentamos a pesquisa que realizamos, bem como os dados que pudemos apreender a partir da leitura dos artigos disponibilizados para acesso no site do arquivo do jornal.

\section{A representação do genocídio armênio no New York Times: 1915}

Nessa parte analisaremos os dados obtidos por meio da pesquisa a fim de apresentar a disposição dos textos disponíveis no jornal New York Times, mês a mês durante todo o ano de 1915 e também buscamos identificar os principais temas retratados neste jornal sobre o genocídio armênio. Optamos por apresentar os dados sistematizados com a quantidade e o percentual apenas para tornar a compreensão mais facilitada.

No quadro 1 se observa a distribuição mês a mês do ano de 1915 e a quantidade de textos produzidos sobre o genocídio armênio pelo New York Times, considerando-se a amostra consultada no arquivo digital já mencionado do jornal.

\footnotetext{
${ }^{8}$ Antaramián, 2016, p. 339.
} 
Quadro 1. Textos publicados pelo jornal New York Times sobre o genocídio armênio em 1915. Disposição de dados - meses/quantidade de artigos/percentual

\begin{tabular}{|c|c|c|}
\hline Mês & Quantidade & Percentual \\
\hline Janeiro & 2 & $3,13 \%$ \\
\hline Fevereiro & 5 & $7,81 \%$ \\
\hline Março & 2 & $3,13 \%$ \\
\hline Abril & 4 & $6,25 \%$ \\
\hline Maio & 2 & $3,13 \%$ \\
\hline Junho & 4 & $6,25 \%$ \\
\hline Julho & 18 & $28,13 \%$ \\
\hline Agosto & 5 & $7,81 \%$ \\
\hline Setembro & 12 & $18,75 \%$ \\
\hline Outubro & 4 & $6,25 \%$ \\
\hline Novembro & 2 & $3,13 \%$ \\
\hline Dezembro & 5 & $7,81 \%$ \\
\hline Total & 64 & $101,58 \%$ \\
\hline
\end{tabular}

Fonte: Os autores, 2019.

$\mathrm{Na}$ apresentação do percentual da tabela em questão arredondamos valores fracionados, motivo pelo qual o valor total extrapola a escala de $100 \%$.

Este quadro nos permite deduzir que os meses de maior produção de artigos sobre o genocídio armênio pelo New York Times foram em julho e setembro, respectivamente. De acordo com as fontes que consultamos, foi a partir de abril de 1915 que as agressões ao povo armênio se tornaram mais incisivas.

Foi neste mês que se intensificou a perseguição aos intelectuais armênios e também à figuras populares que foram levados ao interior do país e cruelmente assassinados. Todos os líderes políticos armênios foram presos e encaminhados para centros de trabalho, nomeados por Oliveira e Rodrigues (2018) como campos de trabalho forçado. De acordo com os autores, "os que não pereciam frente às condições de labor, eram assassinados" ${ }^{10}$. Esse processo teve início no dia 24 de abril e ficou conhecido como Domingo Vermelho. Ulteriormente convencionouse que o dia 24 de abril seria o Dia de Memória do Genocídio. Supomos que com a ampliação das ações agressivas atingindo personalidades armênias, esse genocídio tenha conferido maior material para que o New York Times pudesse ampliar o escopo de textos.

Antaramián (2016) destaca que essa seria a primeira fase ou estágio do genocídio, uma vez que dessa maneira seria possível a eliminação de toda cúpula armênia pensante. Para o autor, a eliminação dos intelectuais surge como algo extremamente importante, pois esses seriam os que poderiam influenciar outros grupos a não aceitar a situação desenhada. Esta atitude tinha como objetivo "eliminar a cúpula pensante, aquela que teria a possibilidade de condenar de maneira mais efetiva o plano de extermínio"11. Além de combater os intelectuais e pessoas públicas armênias, passou-se a construir uma imagem de que esses segmentos seriam influentes no suposto processo de traição armênia. O exército turco se apropriou e ventilou esse discurso e foi o grande executor da ação idealizada. Era essa instituição que organizava a logística das ações e as executava.

\footnotetext{
${ }^{10}$ Oliveira, Rodrigues, 2018, p. 1202.

${ }^{11}$ Antaramián, 2016, p. 346, tradução nossa.
} 
Antaramián também destaca o que considera como uma segunda etapa do genocídio. Esta ocorreu também em 1915, quando em plena Primeira Guerra Mundial, a Turquia se uniu a Alemanha, Áustria e a Hungria, motivo pelo qual o governante da cidade de Val, Jevdet Bei, exigiu a apresentação de 4.000 soldados armênios para o recrutamento junto ao exército. Esta atitude, cujo objetivo era eliminar os homens fisicamente e em idade de combater e que resultou na morte de um grande número de soldados foi, no entender de Antaramián, uma estratégia do governo turco para assassinar o maior número possível de armênios. Estas são suas palavras:

los conscriptos armenios fueron transformados en soldados/obreros (amele taburi) destinados a construir caminos y vías férreas para luego ser aniquilados en puestos de retaguardia como "carne de cañón”, al tiempo que otros fueron fusilados en trincheras construidas por ellos mismos. Fueron pocos los que sobrevivieron a las ejecuciones sumarias por parte de sus propios compañeros, los soldados y oficiales turcos ${ }^{12}$.

É preciso ainda destacar que em vários artigos está enfatizado que correspondentes do New York Times obtiveram informações e contatos com aqueles que conseguiram fugir da Turquia. Isso amplia também o acesso do jornal a dados e situações. Há ainda relatos de correspondentes que estabeleceram contato com responsáveis por retirar armênios da Turquia ou com pessoas que apresentavam qualquer relação com essa retirada.

O artigo que indica a preocupação de Henry Morgenthau, na época embaixador dos Estados Unidos, com a retirada de armênios promovida por Zaven Der Yeghiayein, também é do mês de abril. Contatos como esse e com pessoas que vivenciaram a situação do genocídio conferiram maior substrato para os artigos publicados, já que para que a informação fosse veiculada pelo jornal era necessário identificar maiores dados sobre aqueles que forneceram as informações. Nesse sentido, é lícito observar ainda que são os artigos a partir do mês de abril os que trazem maiores detalhes sobre a situação vivenciada pelo povo armênio naquele contexto.

Para que possamos nos aproximar dos temas publicados pelo New York Times, na sequência apresentaremos a distribuição dos principais assuntos presentes em cada um dos artigos. Realizamos a leitura/tradução dos artigos e os agrupamos segundo o tema preponderante do texto. Isso porque apesar de apresentar textos curtos, num formato comum a jornais, havia muitas informações apresentadas. Assim, partimos do núcleo central dos artigos (quadro 2).

\footnotetext{
12 Antaramián, 2016, p. 348.
} 
Quadro 2. Temas publicados pelo New York Times em 1915 sobre o genocídio armênio (temas/ quantidade de artigo/percentual)

\begin{tabular}{|c|c|c|}
\hline Tema & Quantidade & Percentual \\
\hline $\begin{array}{c}\text { Apelo do papa } \\
\begin{array}{c}\text { Ataques a navios, submarinos e } \\
\text { afogamentos }\end{array}\end{array}$ & 01 & $1,57 \%$ \\
\hline Espiões turcos & 06 & $9,40 \%$ \\
\hline Informações sobre o genocídio & 01 & $1,57 \%$ \\
\hline $\begin{array}{c}\text { Intervenções de resgate e } \\
\text { pedidos pelo fim do genocídio }\end{array}$ & 31 & $17,19 \%$ \\
\hline $\begin{array}{c}\text { Necessidades de saúde e } \\
\text { alimentação dos armênios }\end{array}$ & 11 & $3,13 \%$ \\
\hline Negação do genocídio & 02 & $7,82 \%$ \\
\hline Refugiados & 05 & $4,69 \%$ \\
\hline Resistência & 03 & $6,25 \%$ \\
\hline Total & 04 & $100,06 \%$ \\
\hline
\end{tabular}

Fonte: Os autores, 2019.

$\mathrm{Na}$ apresentação do percentual da tabela em questão arredondamos valores fracionados, motivo pelo qual o valor total extrapola a escala de $100 \%$.

Para esta análise, optamos pela apresentação resumida do conteúdo dos artigos iniciando por aqueles com menor percentual. Usaremos os mesmos termos apresentados na tabela.

\section{Apelo papal}

Em um dos artigos consultados, se observa o apelo do papa Bento XV aos governantes do Império Otomano, a través de correspondência, para que se pusesse fim ao genocídio ${ }^{13}$. A notícia retrata que o papa teria pedido, via carta, aos governantes do Império Otomano para que interrompessem a matança. Não há indicação de qualquer retorno às colocações do líder religioso.

\section{Espiões turcos}

Também observamos que houve um artigo ${ }^{14}$ que retratava ações de espiões turcos que teriam se hospedado em um hotel em busca de armênios que estariam escondidos, o que confirma que os turcos passaram a perseguir os armênios em todos os possíveis locais em que esses estivessem escondidos. A notícia, no entanto, não deixa claro se os armênios foram ou não encontrados pelos turcos, mas nos apresenta uma modalidade diferenciada de perseguição não apresentada pelos teóricos que estudamos e que retratam a situação do genocídio.

\footnotetext{
${ }^{13}$ POPE MAY MAKE NEW PLEA TO KAISER. T. P. O'Connor Hears He Will Be Asked to Take Action to Save the Armenians <https://www.nytimes.com/1915/12/09/archives/pope-may-make-new-plea-to-kaiser-tp-oconnorhears-he-will-be-asked.html> .

${ }^{14}$ TURKISH SPIES IN HOTEL. Glared at an Armenian, but House Detective Chased Them Away <https://www.nytimes.com/1915/10/29/archives/turkish-spies-in-hotel-glared-at-an-armenian-but-housedetective.html>.
} 


\section{Deficiências alimentares e de acesso aos serviços}

Com relação aos artigos ${ }^{15}$ que destacam as dificuldades pelas que passavam os armênios na Turquia para conseguir alimentos e as suas precárias condições ao acesso ao atendimento de saúde, o New York Times retrata, antes de abril de 1915, situações de privações, dentre as quais são apontadas a dificuldade de obter alimentos e de acesso aos serviços de saúde. Os artigos apresentam situações em que os armênios não conseguiam comprar alimentos e ainda casos em que os serviços de saúde negligenciam o atendimento de armênios doentes.

\section{Refugiados}

Os artigos que tratam de refugiados ${ }^{16}$ mostravam solidariedade para com as pessoas nessas condições, entre as que incluímos a postura do embaixador dos EUA que garantiu apoio àqueles que ajudassem os armênios a fugir do território turco. Os dados sobre o incremento de refugiados armênios que residiam na Turquia suscitaram uma grande preocupação por parte do embaixador dos EUA, no que se refere a capacidade para recebe-los em seu país, como mostra New York Times. Mas também retratam povos como os gregos que foram colocados em situação de exílio, contra a sua vontade. $\mathrm{O}$ artigo enfatiza que muitos morriam de fome no processo de extradição. E, ainda há menções, nesses textos, ao grande contingente de armênios que deixavam o país alcançando a fronteira russa. Em ambos casos observamos que a condição dos refugiados também era extremamente precária uma vez que os povos eram expostos a condições sub humanas. Muitos deles acabavam morrendo no percurso ao exílio dadas a precariedade das situações e aos riscos a que estavam expostos.

\section{Resistência armênia}

Com relação à resistência de armênios, encontramos quatro $\operatorname{artigos}^{17}(6,25 \%$ do total) que abordam tanto o caso das guerrilhas armênias que se formaram, assim como a sua resistência

15 100,000 ARMENIANS IN NEED. Central Relief Committee at Tiflis Cables Here for Help $<$ https://www.nytimes.com/1915/01/21/archives/100000-armenians-in-need-central-relief-committee-at-tifliscables.html .

600,000 DRIVEN INTO EXILE Unless Neutral Powers Intervene, Says Nubar Pasha, Almost the Whole People Is Doomed <https://spiderbites.nytimes.com/1915/articles_1915_05_00000.html>.

16 600,000 STARVING ON ROAD Adds That More Than 100,000 Greeks Have Been Deported from the Mediterranean Coast <https://spiderbites.nytimes.com/1915/articles_1915_05_00000.html>.

ARMENIAN REFUGEES NUMBER THOUSANDS. 8,000 Have Already Crossed the Russian Frontier - In a Pitiable Condition <https://www.nytimes.com/1915/01/15/archives/armenian-refugees-number-thousands-8000have-already-crossed-the.html>.

MILLION ARMENIANS KILLED OR IN EXILE; American Committee on Relief Says Victims of Turks Are Steadily Increasing. POLICY OF EXTERMINATION More Atrocities Detailed in Support of Charge That Turkey Is Acting Deliberately <https://www.nytimes.com/1915/12/15/archives/million-armenians-killed-or-in-exileamerican-committee-on-relief.html $>$.

${ }^{17}$ ARMENIANS' HEROIC STAND IN MOUNTAINS. Men, Women, and Children Fought with Knives, Scythes, and Stones <Disponível em https://www.nytimes.com/1915/11/27/archives/armenians-heroic-stand-inmountains-men-women-and-children-fought.html>.

FROM AMERICA TO FIGHT. Detachment of Armenians Welcomed Enthusiastically at Tiflis <https://spiderbites.nytimes.com/1915/articles_1915_05_00000.html>.

GUERRILLA WARFARE IN ARMENIA < https://www.nytimes.com/1915/06/18/archives/guerrilla-warfare-inarmenia.html>.

ROUTED TURKISH ARMY PURSUED BY RUSSIANS. Armenians Hold Van Against Turks and Kurds Massacre of Villagers Continues <https://www.nytimes.com/1915/05/06/archives/routed-turkish-army-pursuedby-russians-armenians-hold-van-against.html $>$. 
em relação ao genocídio. Nessas descrições temos relatos de investidas armênias visando autodefesa em que homens, mulheres e crianças tiveram que recorrer às armas. Esse conflito, transcorrido em uma montanha, apresentava os armênios armados com facas, foices e pedras. No entanto o New York Times os retrata como heróis, como pessoas que só recorreram a esse subterfúgio para garantir a sua sobrevivência em meio aos ataques a que estavam subjugados.

Figura ainda que os Estados Unidos teriam até considerado mobilizar tropas para que fossem até a região interferir no conflito, porém não há indicação sobre o fato de que essa intervenção tivesse acontecido ou não. É importante ressaltar que a partir de abril tivemos também o desarmamento dos armênios, ou seja, esses povos não tinham sequer como resistir aos ataques sofridos ${ }^{18}$.

\section{A negação do genocídio}

Há artigos que demonstram a negativa do estado turco e de outros estados de que o genocídio estivesse acontecendo. Altaramián (2016) nos coloca que apesar do genocídio ter sido planejado previamente e de haver resultado em elevados índices de morte de armênios há uma tentativa enorme do governo turco e de outros estados em negar que o mesmo tivesse acontecido. Aliás, há muitos países que ainda hoje não reconheceram a ocorrência do genocídio. O New York Times nos apresenta cinco artigos nos quais a negação é demonstrada.

Um desses textos apresenta a negação do genocídio pelo primeiro ministro alemão, que afirmou que os próprios armênios organizaram represálias contra eles mesmos. Há ainda uma manifestação da Alemanha, que, segundo nota divulgada pelo governo turco, o genocídio não estaria em curso. Também sobre a Alemanha, país de origem de grande parte das armas utilizadas no genocídio ${ }^{19}$, encontramos na publicação de um importante jornal, o Vossische Zeitung, uma notícia justificando os atos do governo turco cometidos contra o povo armênios, como se fossem um ato ético, correto. Dessa forma o jornal nega o genocídio e o apresenta como algo positivo.

Também tivemos acesso a um artigo em que o próprio Estado turco nega o genocídio. Esta negação, que persiste até hoje, busca, a nosso ver, encobrir o banho de sangue armênio promovido naquele país através da sanção do Estado. No quesito "negação" há ainda uma manifestação do secretário dos Estados Unidos à época dos fatos, Willian Jennings Bryan de que não iria tecer qualquer comentário sobre o genocídio armênio apesar dos Estados Unidos, em dadas circunstâncias, destacar sua contraposição ao mesmo ${ }^{20}$.

\footnotetext{
${ }^{18}$ Oliveira, Rodrigues, 2018.

${ }^{19}$ Como afirmam Oliveira e Rodrigues, 2018.

20 ARMENIAN ATROCITIES SCOUTED BY BERNSTORFF. Calls Reports "Pure Inventions". Says the Catholicos Wrote Under Pressure <https://www.nytimes.com/1915/09/28/archives/armenian-atrocities-scoutedby-bernstorff-calls-reports-pure.html $>$.

BRYAN REFUSES TO COMMENT. Has Nothing to Say About Sinking of the Armenian $<$ https://www.nytimes.com/1915/07/01/archives/bryan-refuses-to-comment-has-nothing-to-say-about-sinkingof-the.html $>$.

CAN'T DEFEND ARMENIANS. Turkish Statesman Says Government Has No Gendarmes in Interior <https://www.nytimes.com/1915/10/25/archives/cant-defend-armenians-turkish-statesman-says-government-hasno.html>.

DEFENDS SUBMARINE'S ACT. Vossische Zeitung Thinks the Armenian Was Destroyed Legally. <https://www.nytimes.com/1915/07/04/archives/defends-submarines-act-vossische-zeitung-thinks-the-armenianwas.html>.
} 


\section{O apoio ao povo armênio}

Com relação aos artigos que apresentam propostas de resgate de armênios e pedidos pelo fim do genocídio, este advém de políticos e personalidades da época ${ }^{21}$. Três textos abordavam situações relacionadas ao resgate dos armênios. Em um deles há a descrição de um nadador armênio que teria conseguido salvar uma criança que estava em uma cabana uma hora antes de um grande massacre na vila em que residia. Outro texto destaca a possibilidade de haver um novo apelo do papa em prol do resgate dos armênios. O texto fortalece a ideia de que o papa pretendia manifestar-se novamente sobre o fim da matança. Em um último texto há a descrição do Comitê Britânico comentando que retomaria as ações de suporte aos armênios, buscando resgatá-los do local em que residiam.

Outros textos demonstram retaliações por parte dos Estados Unidos e da Rússia em relação ao Estado Turco caso as matanças continuassem ${ }^{22}$. Há ainda manifestações da embaixada norteamericana pedindo o fim dos extermínios, assim como colocações de Washington com a mesma conotação. Há ainda apelações por parte de cardeais da Igreja Católica, e mesmo uma colocação proveniente de Berlim de que a Alemanha buscaria investigar melhor os navios nos quais se encontravam armênios, evitando assim possíveis matanças. Este último é, em tese, um aspecto atípico uma vez que na época dos fatos a Alemanha negava que os mesmos acontecessem.

GERMANY PROTESTED ARMENIAN MASSACRES. Dr. Barton Quotes Embassy Note to Turkish Government Presented Last August <https://www.nytimes.com/1915/12/23/archives/germany-protestedarmenian-massacres-dr-barton-quotes-embassy-note.html>.

${ }^{21}$ APPEAL SENT TO WILSON By Head of Church - Evidences of Fearful Outrages Seen in Deserted Settlements < https://spiderbites.nytimes.com/1915/articles_1915_05_00000.html>.

CABIN BOY'S STORY. Lad from the Armenian Swam for an Hour Before Rescue $<$ https://www.nytimes.com/1915/07/02/archives/cabin-boys-story-lad-from-the-armenian-swam-for-an-hourbefore.html>.

BRITISH COMMITTEE ACTIVE Resolves to Work On Despite the Terrible Events That Have Stopped Its Work for Armenia <https://spiderbites.nytimes.com/1915/articles_1915_05_00000.html>.

${ }^{22}$ 500,000 ARMENIANS SAID TO HAVE PERISHED. Washington Asked to Stop Slaughter of Christians by Turks and Kurds <https://www.nytimes.com/1915/09/24/archives/500000-armenians-said-to-have-perishedwashington-asked-to-stop.html $>$.

ALLIES TO PUNISH TURKS WHO MURDER; Notify Porte That Government Heads Must Answer for Armenian Massacres <https://www.nytimes.com/1915/05/24/archives/allies-to-punish-turks-who-murder-notifyporte-that-government.html >.

BRYCE ASKS US TO AID ARMENIA. Says That All the Christians in Trebizond, Numbering 10,000, Were Drowned <https://www.nytimes.com/1915/09/21/archives/bryce-asks-us-to-aid-armenia-says-that-all-thechristians-in.html>.

MISSION BOARD TOLD OF TURKISH HORRORS. Correspondents Confirm the Reports of the Wiping Out of Armenians <https://www.nytimes.com/1915/09/17/archives/mission-board-told-of-turkish-horrorscorrespondents-confirm-the.html>.

MORGENTHAU INTERCEDES. Reports Great Uneasiness Over Treatment of Armenians <https://www.nytimes.com/1915/04/29/archives/morgenthau-intercedes-reports-great-uneasiness-over-

treatment-of.html>.

NATIONAL PROTEST URGED Suggestion That Germany and Austria Be Held Responsible. Outrages on Americans < https://spiderbites.nytimes.com/1915/articles_1915_05_00000.html>.

WASHINGTON AWAITS FACTS. Wants Full Report of Status and Conduct of the Armenian $<$ https://www.nytimes.com/1915/07/02/archives/washington-awaits-facts-wants-full-report-of-status-andconduct-of.html $>$.

BERLIN DEFENDS SINKING Copenhagen Hears Germany Will Suggest Joint Inspection of Ships Leaving Here. Germans Think Armenian Affair Helps Their Case. President Hears Berlin Will Reply on July <https://spiderbites.nytimes.com/1915/articles_1915_05_00000.html>. 


\section{Afogamentos e ataques aos navios nos quais se encontravam armênios}

Com referência aos relatos de ataques a navios em que se encontravam armênios e sobre seus afogamentos (9,40\% dos artigos analisados) e as informações sobre o genocídio (48,44\% dos artigos analisados), os reunimos em um único grupo porque ambos estão extremamente relacionados.

Os ataques a navios retratam o afundamento de navios com armênios que tentavam sair do país, mas também de mulheres, idosos e crianças deportados. As descrições apontam o caso de um submarino que foi usado para derrubar uma dessas embarcações, apesar de que no começo dos massacres o governo turco oferecia aos armênios a possibilidade de deixar o país ${ }^{23}$.

As descrições de afogamentos de armênios a través do afundamento dos seus navios, visando como único fim a sua morte, são vários ${ }^{24}$ e ocorria após os embarques dos armênios, o que significa que atrás da deportação se escondida a intenção insidiosa de exterminar este povo.

Para Antaramián (2016) os afogamentos eram uma metodologia comumente usada pelo governo turco para exterminar os armênios, sobretudo junto aos que buscavam fugir do país. Nessa fase destacaram-se figuras como a dos carrascos ou "verdugos" que eram responsáveis por organizar os ataques aos navios. Para isto, segundo este autor, o Estado turco contava com a figura de Djemal Azmi como um dos responsáveis por afundar os navios e por provocar o afogamento de armênios. Caberia ao carrasco ou ao "verdugo", em tese, "[...] afogar as caravanas que lhe correspondiam" 25 .

Além disto, Antaramián (2016) salienta que em alguns casos os armênios eram convidados a peregrinar caminhando até os portos e que muitos morriam no translado porque eram expostos a uma gama de riscos enorme. Isso também acontecia com aqueles que tentavam fugir, pois, não conseguiam sobreviver as intercorrências vivenciadas no translado.

Uma das descrições do New York Times menciona a destruição de portos para evitar embarque e, sobretudo, desembarque de navios de armênios refugiados.

\footnotetext{
23 Altaramián, 2016.

24 ARMENIAN SURVIVORS HERE. Muleteers Assert They Were Kicked Into Water by Submarine Crew <https://www.nytimes.com/1915/07/14/archives/armenian-survivors-here-muleteers-assert-they-were-kickedinto.html>.
}

ATTACK AIMED AT US? London Standard So Construes Sinking of the Armenian <https://www.nytimes.com/1915/07/03/archives/attack-aimed-at-us-london-standard-so-construes-sinking-ofthe.html>.

MASSACRE BY TURKS IN CAUCASUS TOWNS; Armenians Led Out Into the Streets and Shot or Drowned Old Friends Not Spared <https://www.nytimes.com/1915/02/23/archives/massacre-by-turks-in-caucasus-townsarmenians-led-out-into-the.html>.

NEW WAR LESSON IN ARMENIAN CASE. Attack on Mule Ship Shows the Latest Type of Submarine <https://www.nytimes.com/1915/07/03/archives/new-war-lesson-in-armenian-case-attack-on-mule-ship-showsthe.html>.

PARIS CALLS IT DEFIANCE. Say Armenian Sinking Is the Real German Answer to Our Notes <https://www.nytimes.com/1915/07/03/archives/paris-calls-it-defiance-say-armenian-sinking-is-the-realgerman.html>.

WILSON RELIEVED OVER THE ARMENIAN. Steamer Was "Engaged in Admiralty Business," President Learns Through Ambassador Page <https://www.nytimes.com/1915/07/02/archives/wilson-relieved-over-thearmenian-steamer-was-engaged-in-admiralty.html>.

${ }^{25}$ Antaramián, p. 349, tradução nossa. 


\section{Outras formas de massacre}

As informações gerais sobre o genocídio são descrições, algumas delas relatos de vítimas, e outras de correspondentes, e apresentam diversas formas de tortura e morte dos armênios, como: fuzilamentos no deserto e em planícies, queima de armênios vivos e outros massacres generalizados. Encontramos descrições nas quais os armênios eram levados pelos turcos pelo deserto sob o argumento de que seriam exilados e lá eram exterminados com armas de fogo e informações sobre a forma de tratamento conferida às mulheres e crianças no contexto do genocídio. Isso integraria, segundo Antaramián a denominada terceira fase do genocídio:

Con el pretexto de trasladar a los armenios desde las zonas de combate en el frente de guerra hacia lugares más seguros, inculpándolos de cooperar con el enemigo y de que estaban en una inminente rebelión a escala nacional, comenzó la deportación y exterminio de la masa popular con destino final a los desiertos de Siria y Mesopotamia. Las deportaciones iniciaron el 25 de mayo de 1915 y se componían predominantemente de mujeres, ancianos y niños, quienes eran sometidos a situaciones extremas para provocar su muerte por inanición o enfermedad ${ }^{26}$.

Em tese, o autor destaca o genocídio como algo processual, e sua plena expansão aconteceria a partir da intensificação das agressões. Dessa forma, o autor chama a nossa atenção ao fato de que é nesse momento que as agressões se tornam mais violentas, desmedidas.

Os fuzilamentos no deserto e em planícies ${ }^{27}$, onde haviam assentamentos de armênios, figuram como uma modalidade de morte premeditada e previamente calculada. Conforme descrição dos textos, os turcos se dirigiam para esses locais e armavam emboscadas para os armênios, resultando em muitas mortes. Os fuzilamentos consistiam em uma prática corriqueira segundo a qual os turcos disparavam aleatoriamente contra os armênios. No entanto, os ataques de extermínio também aconteciam com uso de espadas.

Poucos eram os armênios que conseguiam escapar a essas estratégias tão violentas. Igualmente cruel foi o fato de queimar armênios vivos, trancados em um edifício de madeira. De acordo com o artigo foram mortos nessa ação uma média de 1000 armênios $^{28}$.

Os relatórios elaborados por vítimas e também por correspondentes jornalísticos narram a crueldade dos atos cometidos. Um dos textos chega a destacar também que em dada circunstância búlgaros também foram fuzilados junto aos armênios ${ }^{29}$. Há um texto que enfatiza a posição da Alemanha em proteger os turcos, como se os massacres não existissem. ${ }^{30}$ Nesse

\footnotetext{
${ }^{26}$ Antaramián, 2016, p. 349.

${ }^{27}$ APPEAL SENT TO WILSON By Head of Church - Evidences of Fearful Outrages Seen in Deserted Settlements < https://spiderbites.nytimes.com/1915/articles_1915_05_00000.html>.

ARMENIANS ARE SENT TO PERISH IN DESERT. Turks Accused of Plan to Exterminate Whole Population. People of Karahissar Massacred <https://www.nytimes.com/1915/08/18/archives/armenians-are-sent-to-perishin-desert-turks-accused-of-plan-to.html $>$.

28 BURN 1,000 ARMENIANS. Turks Lock Them in a Wooden Building and Then Apply the Torch <https://www.nytimes.com/1915/08/20/archives/burn-1000-armenians-turks-lock-them-in-a-wooden-buildingand-then-a.html>.

29 BULGARS AND ARMENIANS. Doubt Cast Upon the Report of a Massacre at Adrianople <https://www.nytimes.com/1915/12/23/archives/bulgars-and-armenians-doubt-cast-upon-the-report-of-amassacre-at-a.html>.

30 GERMANY PROTESTED ARMENIAN MASSACRES. Dr. Barton Quotes Embassy Note to Turkish Government Presented Last August. <https://www.nytimes.com/1915/12/23/archives/germany-protestedarmenian-massacres-dr-barton-quotes-embassy-note.html $>$.
} 
texto é também enfatizada a utilização dos fuzilamentos como meio para dizimar este grupo social.

Os massacres são relatados na maioria dos textos. Em tese o massacre corresponde à morte provocada com crueldade e atingindo grandes contingentes populacionais. Os exemplos que citamos também podem ser considerados massacres, ainda que os demais textos não apresentem características como o fuzilamento e a queima de armênios vivos. Descrevem invasões turcas em cidades e vilarejos, chegando até a narrar a extinção de vilas inteiras de armênios por parte dos turcos. Encontramos muitas descrições de armênios que foram expulsos de suas casas e abandonados ao ermo nas cidades, vivenciando processos de profunda exclusão social bem como dificuldades pela própria sobrevivência ${ }^{31}$.

Com relação ao número de mortos nos massacres, encontramos textos ${ }^{32}$ que elaboram uma breve análise dos eventos que marcaram o genocídio e, na sequência, a apresentação do total de mortos. Os artigos publicados pelo New York Times no mês de fevereiro de 1915 apontavam uma estimativa de 56 mil mortos. Um dos textos publicado em julho indicava que em um único ataque turcos teriam dizimado uma média de 30.000 mil mortos. Já os textos publicados pelo jornal em setembro, com apenas uma semana de diferença indicam de 450.000 a 500.000 mil mortos no total, desde que o genocídio tinha sido iniciado.

Há ainda outros artigos que apresentam o genocídio usando o termo "atrocidade". Nesses textos é feita menção ao termo: "atrocidade turca" para designar as condutas de agressão dos turcos contra os armênios e demais povos perseguidos. Há nesse sentido analogias entre a manutenção das atrocidades pelos turcos e as tratativas conferidas pela Alemanha e há manifestações que que o genocídio armênio não deixava de ser uma das maiores agressões possíveis contra o gênero humano. ${ }^{31}$ KURDS MASSACRE MORE ARMENIANS. All Inhabitants in Ten Villages Near Van Said to Have Been
Killed <https://www.nytimes.com/1915/04/26/archives/kurds-massacre-more-armenians-all-inhabitants-in-ten-
villages-near.html>.

KURDS RENEW MASSACRES. Attacks on Christians in Armenia Become Violent <https://spiderbites.nytimes.com/1915/articles_1915_05_00000.html>.

SCATTERED OVER EMPIRE Christian Cities Cease to Exist as Such and Inhabitants Are Driven Far from Home <https://spiderbites.nytimes.com/1915/articles_1915_05_00000.html>.

SCATTERED OVER EMPIRE Christian Cities Cease to Exist as Such and Inhabitants Are Driven Far from Home < https://spiderbites.nytimes.com/1915/articles_1915_05_00000.html>.

TURKS ARE EVICTING NATIVE CHRISTIANS. Greeks and Armenians Driven From Homes and Converted by the Sword, Assert Americans <https://www.nytimes.com/1915/07/12/archives/turks-are-evicting-nativechristians-greeks-and-armenians-driven.html $>$.

TURKS DEPOPULATE TOWNS OF ARMENIA. Traveler Reports Christians of Great Territory Have Been Driven from Homes <https://www.nytimes.com/1915/08/27/archives/turks-depopulate-towns-of-armeniatraveler-reports-christians-of.html>.

${ }^{32}$ SAYS EXTINCTION MENACES ARMENIA. Dr. Gabriel Tells of More Than 450,000 Killed in Recent Massacres < https://www.nytimes.com/1915/09/25/archives/says-extinction-menaces-armenia-dr-gabriel-tellsof-more-than.html>.

TALES OF ARMENIAN HORRORS CONFIRMED. Committee on Athrocities Says 500,000 Victims Have Suffered Already <https://www.nytimes.com/1915/09/27/archives/tales-of-armenian-horrors-confirmedcommittee-on-athrocities-says.html>.

TURKS MASSACRE ARMENIANS OF ISMID; Burn the Asia Minor Port, Only 56 Miles from Constantinople <https://spiderbites.nytimes.com/1915/articles_1915_05_00000.html>.

TURKS HARD PRESSED IN TURKISH ARMENIA. Russians Attacking 30,000 East of Bitlis -More Armenian Massacres <https://www.nytimes.com/1915/07/13/archives/turks-hard-pressed-in-turkish-armenia-russiansattacking-30000-east.html>. 
Nesses textos há descrição ainda de um armênio que atacou um turco que teria matado sua mãe com uma bomba, há descrições de declarações que somente $10,0 \%$ dos armênios não seriam deportados por parte do governo turco e há também menções de que as fugas dos armênios seriam motivadas por uma atmosfera de medo que se instalou na Turquia ${ }^{33}$. Também encontramos um texto que indica o desespero de armênios que tentavam fugir dos massacres em um voo ${ }^{34}$.

\section{As represálias às mulheres armênias}

Com respeito às mulheres, as ações turcas eram diferenciadas, como nos sugerem os artigos do New York Times ${ }^{35}$. Muitas mulheres eram leiloadas em praça pública, e por conta disso, muitas

33 ARMENIAN'S CREW BRAVE. Capt. Trickey Praises the Conduct of His Men Under Fire <https://www.nytimes.com/1915/07/03/archives/armenians-crew-brave-capt-trickey-praises-the-conduct-of-hismen.html>.

ARMENIANS' OWN FAULT, BERNSTORFF NOW SAYS. They Brought Reprisals on Themselves by Trying to Stir Up Rebellion Against Turkey <https://www.nytimes.com/1915/09/29/archives/armenians-own-faultbernstorff-now-says-they-brought-reprisals-on.html>.

MORE ARMENIAN MASSACRES. Kurdish Atrocities in Bitlis - Armed Armenians Organizing $<$ https://www.nytimes.com/1915/06/06/archives/more-armenian-massacres-kurdish-atrocities-in-bitlis-armedarmenian.html>.

ON VENGEANCE MISSION. Englishman Aboard Armenian Whose Mother Was Killed by Bomb $<$ https://www.nytimes.com/1915/07/04/archives/on-vengeance-mission-englishman-aboard-armenian-whosemother-was.html>.

MONROE AN EX-CIGAR MAN. Victim of Armenian Disaster Well Known in New Orleans <https://www.nytimes.com/1915/07/01/archives/monroe-an-excigar-man-victim-of-armenian-disaster-well-

known-in-new.html>.

RESCUED 5,000 ARMENIANS. French Warships Carried Them from Syria to Egypt <https://www.nytimes.com/1915/09/23/archives/rescued-5000-armenians-french-warships-carried-them-fromsyria-to.html>.

SLAY ALL ARMENIANS IN CITY OF KERASUNT; Turks Wipe Out Entire Population in Town on the Black Sea <https://www.nytimes.com/1915/10/26/archives/slay-all-armenians-in-city-of-kerasunt-turks-wipe-outentire.html>.

TURKS' SOP TO ARMENIANS. Sublime Porte Promises Not to Deport 10 Per Cent. of Them $<$ https://www.nytimes.com/1915/08/25/archives/turks-sop-to-armenians-sublime-porte-promises-not-to-deport10-per.html>.

VON BERNSTORFF ANSWERED German Ambassador's "Pure Inventions" Letter in Regard to Atrocities Causes Indignation <https://spiderbites.nytimes.com/1915/articles_1915_05_00000.html>.

WHOLESALE MASSACRES OF ARMENIANS BY TURKS. Lord Crewe Denounces Influence of the Germans as "an Unmitigated Curse" < https://www.nytimes.com/1915/07/29/archives/wholesale-massacres-of-armeniansby-turks-lord-crewe-denounces.html $>$.

WILSON STUDIES PEACE PLANS. Hears Washington is Not Alarmed Over the Armenian Case <https://www.nytimes.com/1915/07/03/archives/wilson-studies-peace-plans-hears-washington-is-not-alarmedover-the.html>.

${ }^{34}$ STORY OF GREAT EXODUS. Flight from Persia Full of Suffering for Thousands Who Escaped the Sword <https://spiderbites.nytimes.com/1915/articles_1915_05_00000.html>.

35 ALL FINALLY EXTERMINATED. Women Who Had Plunged Knives Into Turks Afterward Killed Themselves <https://spiderbites.nytimes.com/1915/articles_1915_05_00000.html>.

ARMENIAN WOMEN PUT UP AT AUCTION. Refugee Tells of the Fate of Those in Turkish Hands <https://www.nytimes.com/1915/09/29/archives/armenian-women-put-up-at-auction-refugee-tells-of-the-fate-ofthose.html>.

WHOLE PLAIN STREWN BY ARMENIAN BODIES. Turks and Kurds Reported to Have Massacred Men, Women and Children <https://www.nytimes.com/1915/03/20/archives/whole-plain-strewn-by-armenian-bodiesturks-and-kurds-reported-to.html>.

WOMAN DESCRIBES ARMENIAN KILLINGS. German Missionary Says Turks Proclaimed Extermination as Their Aim. FIENDS' WORK IN HARPUT "Let Your Christ Help You!" the Cry as Torture Went 
armênias acabavam cometendo suicídio. Além de servir a prostituição, também eram postas em locais de trabalhos forçados. Há um artigo em que se destaca que os turcos, no momento da agressão, diziam às mulheres que pedissem ajuda para o seu "Cristo". Outro texto relata assassinatos de mulheres e crianças em suas casas e também uma situação em que as mesmas mataram turcos que as atacaram e depois se mataram. De tal forma que temos uma barbárie generalizada em relação a mulheres e também às crianças.

Antaramián (2016) nos coloca que muitas mulheres eram raptadas dos seus lares para servirem em haréns. Essas mulheres eram marcadas com tatuagens que as caracterizavam como mercadorias de uma casa. Ao que parece, o leilão servia tais finalidades. O autor ainda apresenta a situação da prostituição como uma alternativa de sobrevivência das mulheres armênias que não eram aceitas em trabalho formal. Também salienta que esta situação obrigava à muitas mulheres manter relações sexuais com homens que foram responsáveis pela morte de seus familiares. Temos que considerar, portanto, que o contingente de mulheres mortas era grande. Já em relação as crianças que sobreviviam aos ataques o autor nos coloca que havia um destacado número nos orfanatos que ficavam sem qualquer proteção após a morte dos seus pais.

Chartier (2003) compreende que os impressos são atos simbólicos por meio dos quais os homens transmitem o que está escrito. A escrita visa à orientação individual para aquele que lê de maneira solitária. Os impressos substituem a utilização da retórica como meio de instrução e permitem que a orientação, exposta a todos que leem, seja feita individualmente. Dessa forma, a circulação de informações individualmente colabora para a formação de uma opinião pública, comum a vários indivíduos e pode motivar ainda a adoção de dadas práticas sociais. No caso em questão, vemos que o New York Times visava, a nosso ver, formar uma opinião pública sobre o genocídio armênio. E mais, os textos se mostram estruturados de maneira extremamente crítica e em tom de denúncia de um fenômeno que grande parte da sociedade buscou esconder.

\section{Considerações finais}

A fase atribuída ao historiador Peter Burke e que é expressa na sentença: "A função do historiador é lembrar a sociedade daquilo que ela espera esquecer" serve para a análise da situação do genocídio armênio, a nosso ver, de forma exemplar. Nesse sentido, consideramos que a pesquisa em História é basal para que possamos compreender e aprofundar o nosso entendimento sobre todos os fenômenos, sobretudo esses, como o genocídio armênio, um dos eventos que a sociedade espera esquecer ou então, esconder. Partindo da questão da pesquisa, consideramos ainda que os jornais podem se constituir em um importante instrumento de pesquisa histórica. Dada a natureza e finalidade para a qual esse texto foi elaborado, não realizamos também um estudo profundo sobre as fontes, mas uma apresentação resumida dos assuntos que estão contidos nos jornais consultados.

A descrição e apresentação dos textos, no entanto, nos mostrou a perspectiva do New York Times, sempre combativo e crítico junto a temas polêmicos, visando a constituição de uma opinião pública sobre o genocídio. Nos mostrou ainda a força desse meio de comunicação social em identificar as fontes, encaminhar correspondentes, ouvir políticos como o responsável pela embaixada dos Estados Unidos que criticava o genocídio, e apresenta a contraposição alemã

<https://www.nytimes.com/1915/12/12/archives/woman-describes-armenian-killings-german-missionary-saysturks.html>. 
que à época dos fatos negava a ocorrência destas atrocidades. O acesso a todos os artigos, aos 194 artigos citados por Antaramián (2016), com certeza poderia nos dar ainda mais informações sobre a forma de produção dos textos e dos relatos contidos em cada matéria, mas, infelizmente não conseguimos encontrar esses artigos na base de dados on line do jornal.

Além de identificar as atrocidades deflagradas pelo New York Times no período analisado, cumpre a pesquisa histórica desvelar acontecimentos como estes, para que a sociedade possa aprender com eles e realizar um paralelo com a situação contemporânea. O genocídio armênio e seu contexto não devem ser escondidos e nem sublimados, mas compreendidos e conhecidos, para que possamos aprender com nosso passado.

\section{Bibliografia}

ANTARAMIÁN, C. Esbozo histórico del genocidio armenio. Revista Mexicana de Ciencias Políticas y Sociales, Universidad Nacional Autónoma de México, Nueva Época, Año LXI, núm. 228, septiembre-diciembre de 2016. Disponível em <http://www.revistas.unam.mx/index.php/rmcpys/article/view/56>. Acesso em 30 de jan. de 2020.

CHARTIER, R. A história cultural entre práticas e representações. Trad. de Maria Manuela Galhardo. Lisboa: Difusão Editora, 1988.

CHARTIER, R. A Beira da Falésia: a história entre incertezas e inquietude. Porto Alegre: Ed. Universidade/UFRGS, 2002.

CHARTIER, R. Formas de Sentido-Cultura Escrita: entre distinção e apropriação. Campinas: Mercado das Letras, 2003.

LIMA, J. R. de; SANTOS FILHO, I. O. dos. O Jornal Norte-Americano New York Times: Revista Eletrônica de Comunicação, v.07, núm. 2, 2012. Disponível em $<$ http://periodicos.unifacef.com.br/index.php/rec/article/view/895>. Acesso em 30 de jan. de 2020.

OLIVEIRA, A. M.; RODRIGUES, H. W. Rock e Direitos humanos: System of a Down e o genocídio armênio. Revista Direito \& Práxis, Rio de Janeiro, Vol. 9, núm. 3, 2018. Disponível em <http://www.scielo.br/pdf/rdp/v9n3/2179-8966-rdp-9-3-1196.pdf>. Acesso em 30 de jan. de 2020.

\section{Fontes consultadas}

100,000 ARMENIANS IN NEED. Central Relief Committee at Tiflis Cables Here for Help. New York Times, Nova York, 21 de janeiro, 1915. Disponível em $<$ https://www.nytimes.com/1915/01/21/archives/100000-armenians-in-need-central-reliefcommittee-at-tiflis-cables.html> Acesso em 09 de ago. de 2019. 
<https://www.nytimes.com/1915/09/24/archives/500000-armenians-said-to-have-perishedwashington-asked-to-stop.html > Acesso em 09 de ago. de 2019.

600,000 DRIVEN INTO EXILE Unless Neutral Powers Intervene, Says Nubar Pasha, Almost the Whole People Is Doomed. New York Times, Nova York, 12 de setembro, 1915. Disponível em <https://spiderbites.nytimes.com/1915/articles_1915_05_00000.html> Acesso em 09 de ago. de 2019.

600,000 STARVING ON ROAD Adds That More Than 100,000 Greeks Have Been Deported from the Mediterranean Coast. New York Times, Nova York, 25 de agosto, 1915. Disponível em <https://spiderbites.nytimes.com/1915/articles_1915_05_00000.html> Acesso em 09 de ago. de 2019.

ALL FINALLY EXTERMINATED Women Who Had Plunged Knives Into Turks Afterward Killed Themselves. New York Times, Nova York, 27 de novembro, 1915. Disponível em $<$ https://spiderbites.nytimes.com/1915/articles_1915_05_00000.html> Acesso em 09 de ago. de 2019.

ALLIES TO PUNISH TURKS WHO MURDER; Notify Porte That Government Heads Must Answer for Armenian Massacres. New York Times, Nova York, 24 de fevereiro, 1915. Disponível em <https://www.nytimes.com/1915/05/24/archives/allies-to-punish-turks-whomurder-notify-porte-that-government.html> Acesso em 09 de ago. de 2019.

APPEAL SENT TO WILSON By Head of Church - Evidences of Fearful Outrages Seen in Deserted Settlements. New York Times, Nova York, 26 de abril, 1915. Disponível em <https://spiderbites.nytimes.com/1915/articles_1915_05_00000.html> Acesso em 09 de ago. de 2019.

ARMENIAN ATROCITIES SCOUTED BY BERNSTORFF. Calls Reports "Pure Inventions". Says the Catholicos Wrote Under Pressure. New York Times, Nova York, 27 de setembro, 1915. <https://www.nytimes.com/1915/09/28/archives/armenian-atrocities-scouted-by-bernstorffcalls-reports-pure.html> Acesso em 09 de ago. de 2019.

ARMENIAN REFUGEES NUMBER THOUSANDS. 8,000 Have Already Crossed the Russian Frontier - In a Pitiable Condition. New York Times, Nova York, 15 de janeiro, 1915. Disponível em <https://www.nytimes.com/1915/01/15/archives/armenian-refugees-numberthousands-8000-have-already-crossed-the.html> Acesso em 09 de ago. de 2019.

ARMENIAN SURVIVORS HERE. Muleteers Assert They Were Kicked Into Water by Submarine Crew. New York Times, Nova York, 21 de julho, 1915. Disponível em $<$ https://www.nytimes.com/1915/07/14/archives/armenian-survivors-here-muleteers-assertthey-were-kicked-into.html>. Acesso em 09 de ago. de 2019.

ARMENIAN WOMEN PUT UP AT AUCTION. Refugee Tells of the Fate of Those in Turkish Hands. New York Times, Nova York, 03 de setembro, 1915. Disponível em <https://www.nytimes.com/1915/09/29/archives/armenian-women-put-up-at-auction-refugeetells-of-the-fate-of-those.html>. Acesso em 09 de ago. de 2019.

ARMENIANS ARE SENT TO PERISH IN DESERT. Turks Accused of Plan to Exterminate Whole Population. People of Karahissar Massacred. New York Times, Nova York, 18 de 
agosto,1915.Disponível em <https://www.nytimes.com/1915/08/18/archives/armenians-aresent-to-perish-in-desert-turks-accused-of-plan-to.html> Acesso em 09 de ago. de 2019.

ARMENIAN'S CREW BRAVE. Capt. Trickey Praises the Conduct of His Men Under Fire. New York Times, Nova York, 16 de julho, 1915. Disponível em <https://www.nytimes.com/1915/07/03/archives/armenians-crew-brave-capt-trickey-praisesthe-conduct-of-his-men.html> Acesso em 09 de ago. de 2019.

ARMENIANS' HEROIC STAND IN MOUNTAINS. Men, Women, and Children Fought with Knives, Scythes, and Stones. New York Times, Nova York, 27 de novembro, 1915. Disponível em <https://www.nytimes.com/1915/11/27/archives/armenians-heroic-stand-in-mountainsmen-women-and-children-fought.html> Acesso em 09 de ago. de 2019.

ARMENIANS' OWN FAULT, BERNSTORFF NOW SAYS. They Brought Reprisals on Themselves by Trying to Stir Up Rebellion Against Turkey. New York Times, Nova York, 12 de setembro, 1915. Disponível em <https://www.nytimes.com/1915/09/29/archives/armeniansown-fault-bernstorff-now-says-they-brought-reprisals-on.html> Acesso em 09 de ago. de 2019.

ATTACK AIMED AT US?. London Standard So Construes Sinking of the Armenian. New York Times, Nova York, 12 de julho, 1915. Disponível em <https://www.nytimes.com/1915/07/03/archives/attack-aimed-at-us-london-standard-soconstrues-sinking-of-the.html> Acesso em 09 de ago. de 2019.

BERLIN DEFENDS SINKING Copenhagen Hears Germany Will Suggest Joint Inspection of Ships Leaving Here. Germans Think Armenian Affair Helps Their Case. President Hears Berlin Will Reply on July. New York Times, Nova York, 9 de julho, 1915. Disponível em <https://spiderbites.nytimes.com/1915/articles_1915_05_00000.html> Acesso em 09 de ago. de 2019.

BRITISH COMMITTEE ACTIVE Resolves to Work On Despite the Terrible Events That Have Stopped Its Work for Armenia. New York Times, Nova York, 09 de dezembro, 1915. Disponível em <https://spiderbites.nytimes.com/1915/articles_1915_05_00000.html> Acesso em 09 de ago. de 2019.

BRYAN REFUSES TO COMMENT. Has Nothing to Say About Sinking of the Armenian. New York Times, Nova York, 19 de julho, 1915. Disponível em $<$ https://www.nytimes.com/1915/07/01/archives/bryan-refuses-to-comment-has-nothing-tosay-about-sinking-of-the.html> Acesso em 09 de ago. de 2019.

BRYCE ASKS US TO AID ARMENIA. Says That All the Christians in Trebizond, Numbering 10,000, Were Drowned. New York Times, Nova York, 18 de setembro, 1915. Disponível em <https://www.nytimes.com/1915/09/21/archives/bryce-asks-us-to-aid-armenia-says-that-allthe-christians-in.html> Acesso em 09 de ago. de 2019.

BULGARS AND ARMENIANS. Doubt Cast Upon the Report of a Massacre at Adrianople. New York Times, Nova York, 23 de dezembro, 1915. Disponível em <https://www.nytimes.com/1915/12/23/archives/bulgars-and-armenians-doubt-cast-upon-thereport-of-a-massacre-at-a.html> Acesso em 09 de ago. de 2019. 
BURN 1,000 ARMENIANS. Turks Lock Them in a Wooden Building and Then Apply the Torch. New York Times, Nova York, 18 de agosto, 1915. Disponível em <https://www.nytimes.com/1915/08/20/archives/burn-1000-armenians-turks-lock-them-in-awooden-building-and-then-a.html> Acesso em 09 de ago. de 2019.

CABIN BOY'S STORY.Lad from the Armenian Swam for an Hour Before Rescue. New York Times, Nova York, 24 de julho, 1915. Disponível em <https://www.nytimes.com/1915/07/02/archives/cabin-boys-story-lad-from-the-armenianswam-for-an-hour-before.html> Acesso em 09 de ago. de 2019.

CAN'T DEFEND ARMENIANS.Turkish Statesman Says Government Has No Gendarmes in Interior. New York Times, Nova York, 21 de outubro, 1915. Disponível em $<$ https://www.nytimes.com/1915/10/25/archives/cant-defend-armenians-turkish-statesmansays-government-has-no.html> Acesso em 09 de ago. de 2019.

DEFENDS SUBMARINE'S ACT.; Vossische Zeitung Thinks the Armenian Was Destroyed Legally. New York Times, Nova York, 18 de julho, 1915. Disponível em $<$ https://www.nytimes.com/1915/07/04/archives/defends-submarines-act-vossische-zeitungthinks-the-armenian-was.html> Acesso em 09 de ago. de 2019.

FROM AMERICA TO FIGHT.; Detachment of Armenians Welcomed Enthusiastically at Tiflis. New York Times, Nova York, 08 de fevereiro, 1915. Disponível em <https://spiderbites.nytimes.com/1915/articles_1915_05_00000.html> Acesso em 09 de ago. de 2019.

GERMANY PROTESTED ARMENIAN MASSACRES. Dr. Barton Quotes Embassy Note to Turkish Government Presented Last August. New York Times, Nova York, 23 de dezembro, 1915. Disponível em <https://www.nytimes.com/1915/12/23/archives/germany-protestedarmenian-massacres-dr-barton-quotes-embassy-note.html> Acesso em 09 de ago. de 2019.

GUERRILLA WARFARE IN ARMENIA. New York Times, Nova York, 18 de junho, 1915. Disponível em <https://www.nytimes.com/1915/06/18/archives/guerrilla-warfare-inarmenia.html> Acesso em 09 de ago. de 2019.

KURDS MASSACRE MORE ARMENIANS; All Inhabitants in Ten Villages Near Van Said to Have Been Killed. New York Times, Nova York, 26 de abril, 1915. Disponível em $<$ https://www.nytimes.com/1915/04/26/archives/kurds-massacre-more-armenians-allinhabitants-in-ten-villages-near.html> Acesso em 09 de ago. de 2019.

KURDS RENEW MASSACRES. Attacks on Christians in Armenia Become Violent. New York Times, Nova York, 24 de junho, 1915. Disponível em <https://spiderbites.nytimes.com/1915/articles_1915_05_00000.html> Acesso em 09 de ago. de 2019.

MASSACRE BY TURKS IN CAUCASUS TOWNS; Armenians Led Out Into the Streets and Shot or Drowned - Old Friends Not Spared. New York Times, Nova York, 23 de fevereiro, 1915. Disponível em <https://www.nytimes.com/1915/02/23/archives/massacre-by-turks-incaucasus-towns-armenians-led-out-into-the.html> Acesso em 09 de ago. de 2019. 
MILLION ARMENIANS KILLED OR IN EXILE; American Committee on Relief Says Victims of Turks Are Steadily Increasing. POLICY OF EXTERMINATION More Atrocities Detailed in Support of Charge That Turkey Is Acting Deliberately. New York Times, Nova York, 15 de dezembro, $1915 . \quad$ Disponível $\quad$ em $<$ https://www.nytimes.com/1915/12/15/archives/million-armenians-killed-or-in-exileamerican-committee-on-relief.html> Acesso em 09 de ago. de 2019.

MISSION BOARD TOLD OF TURKISH HORRORS. Correspondents Confirm the Reports of the Wiping Out of Armenians. New York Times, Nova York, 22 de setembro, 1915. Disponível em <https://www.nytimes.com/1915/09/17/archives/mission-board-told-ofturkish-horrors-correspondents-confirm-the.html> Acesso em 09 de ago. de 2019.

MONROE AN EX-CIGAR MAN. Victim of Armenian Disaster Well Known in New Orleans. New York Times, Nova York, 19 de julho, 1915. Disponível em $<$ https://www.nytimes.com/1915/07/01/archives/monroe-an-excigar-man-victim-of-armeniandisaster-well-known-in-new.html> Acesso em 09 de ago. de 2019.

MORE ARMENIAN MASSACRES. Kurdish Atrocities in Bitlis - Armed Armenians Organizing. New York Times, Nova York, 06 de junho, 1915. Disponível em $<$ https://www.nytimes.com/1915/06/06/archives/more-armenian-massacres-kurdish-atrocitiesin-bitlis-armed-armenian.html> Acesso em 09 de ago. de 2019.

MORGENTHAU INTERCEDES. Reports Great Uneasiness Over Treatment of Armenians. New York Times, Nova York, 29 de abril, 1915. Disponível em <https://www.nytimes.com/1915/04/29/archives/morgenthau-intercedes-reports-greatuneasiness-over-treatment-of.html> Acesso em 09 de ago. de 2019.

NATIONAL PROTEST URGED Suggestion That Germany and Austria Be Held Responsible. Outrages on Americans. New York Times, Nova York, 11 de setembro, 1915. Disponível em $<$ https://spiderbites.nytimes.com/1915/articles_1915_05_00000.html> Acesso em 09 de ago. de 2019.

NEW WAR LESSON IN ARMENIAN CASE. Attack on Mule Ship Shows the Latest Type of Submarine. New York Times, Nova York, 27 de julho, 1915. Disponível em <https://www.nytimes.com/1915/07/03/archives/new-war-lesson-in-armenian-case-attack-onmule-ship-shows-the.html> Acesso em 09 de ago. de 2019.

ON VENGEANCE MISSION. Englishman Aboard Armenian Whose Mother Was Killed by Bomb. New York Times, Nova York, 18 de julho, 1915. Disponível em <https://www.nytimes.com/1915/07/04/archives/on-vengeance-mission-englishman-aboardarmenian-whose-mother-was.html> Acesso em 09 de ago. de 2019.

PARIS CALLS IT DEFIANCE.Say Armenian Sinking Is the Real German Answer to Our Notes. New York Times, Nova York, 10 de julho, 1915. Disponível em <https://www.nytimes.com/1915/07/03/archives/paris-calls-it-defiance-say-armenian-sinkingis-the-real-german.html> Acesso em 09 de ago. de 2019.

POPE MAY MAKE NEW PLEA TO KAISER; T.P. O'Connor Hears He Will Be Asked to Take Action to Save the Armenians. New York Times, Nova York, 15 de dezembro, 1915. 
Disponível em <https://www.nytimes.com/1915/12/09/archives/pope-may-make-new-plea-tokaiser-tp-oconnor-hears-he-will-be-asked.html> Acesso em 09 de ago. de 2019.

RESCUED 5,000 ARMENIANS. French Warships Carried Them from Syria to Egypt. New York Times, Nova York, 10 de setembro, 1915. Disponível em <https://www.nytimes.com/1915/09/23/archives/rescued-5000-armenians-french-warshipscarried-them-from-syria-to.html> Acesso em 09 de ago. de 2019.

ROUTED TURKISH ARMY PURSUED BY RUSSIANS. Armenians Hold Van Against Turks and Kurds - Massacre of Villagers Continues. New York Times, Nova York, 6 de maio, 1915. Disponível em <https://www.nytimes.com/1915/05/06/archives/routed-turkish-armypursued-by-russians-armenians-hold-van-against.html> Acesso em 09 de ago. de 2019.

RUSSIAN SUCCESS CONTINUES; Offensive Movement in Turkish Armenia Still Going On. New York Times, Nova York, 24 de março, 1915. Disponível em <https://www.nytimes.com/1915/03/07/archives/russian-success-continues-offensivemovement-in-turkish-armenia.html> Acesso em 09 de ago. de 2019.

RUSSIANS SAVE ARMENIANS. Troops Arrive at Van and Drive Off Besieging Turks. New York Times, Nova York, 26 de maio, 1915. Disponível em <https://spiderbites.nytimes.com/1915/articles_1915_05_00000.html> Acesso em 09 de ago. de 2019.

RUSSIANS WINNING BELOW THE CAUCASUS. Turkish Influence Waning in Armenia and Persia - Medical Supplies Needed. New York Times, Nova York, 28 de junho, 1915. Disponível em <https://www.nytimes.com/1915/06/28/archives/russians-winning-below-thecaucasus-turkish-influence-waning-in.html> Acesso em 09 de ago. de 2019.

SAYS EXTINCTION MENACES ARMENIA. Dr. Gabriel Tells of More Than 450,000 Killed in Recent Massacres. New York Times, Nova York, 08 de setembro, 1915. Disponível em <https://www.nytimes.com/1915/09/25/archives/says-extinction-menaces-armenia-dr-gabrieltells-of-more-than.html> Acesso em 09 de ago. de 2019.

SCATTERED OVER EMPIRE Christian Cities Cease to Exist as Such and Inhabitants Are Driven Far from Home. New York Times, Nova York, 12 de fevereiro, 1915. Disponível em <https://spiderbites.nytimes.com/1915/articles_1915_05_00000.html> Acesso em 09 de ago. de 2019.

SLAY ALL ARMENIANS IN CITY OF KERASUNT; Turks Wipe Out Entire Population in Town on the Black Sea. New York Times, Nova York, 14 de outubro, 1915. Disponível em <https://www.nytimes.com/1915/10/26/archives/slay-all-armenians-in-city-of-kerasunt-turkswipe-out-entire.html> Acesso em 09 de ago. de 2019.

STORY OF GREAT EXODUS Flight from Persia Full of Suffering for Thousands Who Escaped the Sword. New York Times, Nova York, 26 de abril, 1915. Disponível em <https://spiderbites.nytimes.com/1915/articles_1915_05_00000.html> Acesso em 09 de ago. de 2019.

TALES OF ARMENIAN HORRORS CONFIRMED. Committee on Athrocities Says 500,000 Victims Have Suffered Already. New York Times, Nova York, 16 de setembro, 1915. 
Disponível em <https://www.nytimes.com/1915/09/27/archives/tales-of-armenian-horrorsconfirmed-committee-on-athrocities-says.html> Acesso em 09 de ago. de 2019.

THE LIGHT THAT MAY GO OUT IN TURKEY.; What the Armenians Have Done to Sustain Christianity and Western Civilization in the Household of the Prophet. New York Times, Nova York, 6 de outubro, 1915. Disponível em <https://www.nytimes.com/1915/10/28/archives/thelight-that-may-go-out-in-turkey-what-the-armenians-have-done-to.html > Acesso em 09 de ago. de 2019.

TURKISH SPIES IN HOTEL.; Glared at an Armenian, but House Detective Chased Them Away. New York Times, Nova York, 2 de outubro, 1915. Disponível em $<$ https://www.nytimes.com/1915/10/29/archives/turkish-spies-in-hotel-glared-at-an-armenianbut-house-detective.html> Acesso em 09 de ago. de 2019.

TURKS ARE EVICTING NATIVE CHRISTIANS. Greeks and Armenians Driven From Homes and Converted by the Sword, Assert Americans. New York Times, Nova York, 12 de julho, 1915. Disponível em <https://www.nytimes.com/1915/07/12/archives/turks-areevicting-native-christians-greeks-and-armenians-driven.html> Acesso em 09 de ago. de 2019.

TURKS DEPOPULATE TOWNS OF ARMENIA. Traveler Reports Christians of Great Territory Have Been Driven from Homes. New York Times, Nova York, 27 de agosto, 1915. Disponível em <https://www.nytimes.com/1915/08/27/archives/turks-depopulate-towns-ofarmenia-traveler-reports-christians-of.html> Acesso em 09 de ago. de 2019.

TURKS HARD PRESSED IN TURKISH ARMENIA. Russians Attacking 30,000 East of Bitlis -More Armenian Massacres. New York Times, Nova York, 12 de julho, 1915. Disponível em $<$ https://www.nytimes.com/1915/07/13/archives/turks-hard-pressed-in-turkish-armeniarussians-attacking-30000-east.html> Acesso em 09 de ago. de 2019.

TURKS MASSACRE ARMENIANS OF ISMID; Burn the Asia Minor Port, Only 56 Miles from Constantinople. New York Times, Nova York, 6 de fevereiro, 1915. Disponível em <https://spiderbites.nytimes.com/1915/articles_1915_05_00000.html> Acesso em 09 de ago. de 2019.

TURKS' SOP TO ARMENIANS. Sublime Porte Promises Not to Deport 10 Per Cent. of Them. New York Times, Nova York, 25 de agosto, 1915. Disponível em <https://www.nytimes.com/1915/08/25/archives/turks-sop-to-armenians-sublime-portepromises-not-to-deport-10-per.html> Acesso em 09 de ago. de 2019.

VON BERNSTORFF ANSWERED German Ambassador's "Pure Inventions" Letter in Regard to Atrocities Causes Indignation. New York Times, Nova York, 03 de setembro, 1915. Disponível em <https://spiderbites.nytimes.com/1915/articles_1915_05_00000.html> Acesso em 09 de ago. de 2019.

WASHINGTON AWAITS FACTS. Wants Full Report of Status and Conduct of the Armenian. New York Times, Nova York, 26 de julho, 1915. Disponível em <https://www.nytimes.com/1915/07/02/archives/washington-awaits-facts-wants-full-reportof-status-and-conduct-of.html> Acesso em 09 de ago. de 2019. 
WHOLE PLAIN STREWN BY ARMENIAN BODIES; Turks and Kurds Reported to Have Massacred Men, Women and Children. New York Times, Nova York, 20 de março, 1915. Disponível em <https://www.nytimes.com/1915/03/20/archives/whole-plain-strewn-byarmenian-bodies-turks-and-kurds-reported-to.html> Acesso em 09 de ago. de 2019.

WHOLESALE MASSACRES OF ARMENIANS BY TURKS. Lord Crewe Denounces Influence of the Germans as "an Unmitigated Curse." New York Times, Nova York, 6 de julho, 1915. Disponível em <https://www.nytimes.com/1915/07/29/archives/wholesale-massacresof-armenians-by-turks-lord-crewe-denounces.html> Acesso em 09 de ago. de 2019.

WILSON HEARS OF NEW DISASTER. President Refuses to Make Any Comment on the Sinking of the Armenian. New York Times, Nova York, 10 de julho, 1915. Disponível em $<$ https://www.nytimes.com/1915/07/01/archives/wilson-hears-of-new-disaster-presidentrefuses-to-make-any-comment.html> Acesso em 09 de ago. de 2019.

WILSON RELIEVED OVER THE ARMENIAN. Steamer Was "Engaged in Admiralty Business," President Learns Through Ambassador Page. New York Times, Nova York, 21 de julho, 1915. Disponível em <https://www.nytimes.com/1915/07/02/archives/wilson-relievedover-the-armenian-steamer-was-engaged-in-admiralty.html> Acesso em 09 de ago. de 2019.

WILSON STUDIES PEACE PLANS. Hears Washington is Not Alarmed Over the Armenian Case. New York Times, Nova York, 12 de julho, 1915. Disponível em <https://www.nytimes.com/1915/07/03/archives/wilson-studies-peace-plans-hearswashington-is-not-alarmed-over-the.html> Acesso em 09 de ago. de 2019.

WOMAN DESCRIBES ARMENIAN KILLINGS; German Missionary Says Turks Proclaimed Extermination as Their Aim. FIENDS' WORK IN HARPUT "Let Your Christ Help You!" the Cry as Torture Went On. New York Times, Nova York, 12 de dezembro, 1915. Disponível em <https://www.nytimes.com/1915/12/12/archives/woman-describes-armenian-killings-germanmissionary-says-turks.html> Acesso em 09 de ago. de 2019.

(c) Copyright: Daniela Emilena Santiago Dias de Oliveira, Gabriel Santiago Cristo, 2020.

(c) Copyright: Ar@cne, 2020.

Ficha bibliográfica:

OLIVEIRA, Daniela Emilena Santiago Dias de; CRISTO, Gabriel Santiago. A representação do Genocídio Armênio no New York Times (1915). Ar@cne. Revista Electrónica de Recursos de Internet sobre Geografía y Ciencias Sociales. [En línea]. Barcelona: Universidad de Barcelona, $\mathrm{n}^{\circ} 241,1$ de abril de 2020. ISSN: 1578-0007.

\section{Menú principal de Geo Crítica}

